\title{
Long-term Impact of Mode of Delivery on Stress Urinary Incontinence and Urgency Urinary Incontinence: A Systematic Review and Meta-analysis
}

\author{
Riikka M. Tähtinen ${ }^{a, b}$, Rufus Cartwright ${ }^{c, d}$, Johnson F. Tsui ${ }^{\text {e,f }}$, Riikka L. Aaltonen $^{g}$, \\ Yoshitaka Aoki $^{h}$, Jovita L. Cárdenas ${ }^{i}$, Regina El Dib ${ }^{j}$, Kirsi M. Joronen ${ }^{g}$, Sumayyah Al Juaid ${ }^{k}$, \\ Sabreen Kalantan ${ }^{l}$, Michal Kochana ${ }^{m}$, Malgorzata Kopec ${ }^{m}$, Luciane C. Lopes ${ }^{n, o}$, Enaya Mirza $^{p}$, \\ Sanna M. Oksjoki ${ }^{g}$, Jori S. Pesonen ${ }^{q}$, Antti Valpas ${ }^{r}$, Li Wang ${ }^{s, t}$, Yuqing Zhang ${ }^{u}$, \\ Diane Heels-Ansdell ${ }^{u}$, Gordon H. Guyatt ${ }^{u, v}$, Kari A.O. Tikkinen ${ }^{w, *}$
}

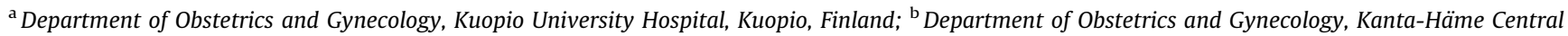
Hospital, Hämeenlinna, Finland; ' Department of Epidemiology and Biostatistics, Imperial College London, London, UK; ${ }^{\mathrm{d}}$ Department of Urogynecology, Imperial College London, London, UK; ${ }^{\mathrm{e}}$ Department of Urology, North Shore-LIJ Lenox Hill Hospital, New York, NY, USA; ${ }^{\mathrm{f}}$ Institute for Bladder and Prostate Research, New York, NY, USA; ${ }^{\mathrm{g}}$ Department of Obstetrics and Gynecology, University of Turku and Turku University Hospital, Turku, Finland; ${ }^{\mathrm{h}}$ Department of Urology, University of Fukui Faculty of Medical Sciences, Fukui, Japan; ${ }^{i}$ Department of Clinical Practice Guidelines, National Center for Health Technology Excellence, México, Mexico; ${ }^{j}$ Department of Anesthesiology, Botucatu Medical School, São Paulo State University, São Paulo, Brazil; ${ }^{\mathrm{k}}$ Department of Obstetrics and Gynecology, King Saud bin Abdulaziz University for Health Sciences, and King Abdulaziz Medical City, Ministry of National Guard Health Affairs, Jeddah, Saudi Arabia; ${ }^{1}$ Department of Obstetrics and Gynecology, King Faisal Specialist Hospital and Research Centre, Riyadh, Saudi Arabia; ${ }^{\mathrm{m}}$ Faculty of Medicine, Jagiellonian University Medical College, Krakow, Poland; ${ }^{\mathrm{n}}$ Pharmaceutical Science Master Courde, University of Sorocaba, São Paulo, Brazil; ${ }^{\circ}$ School of Pharmaceutical Sciences, Department of Drugs and Medications, Paulista State University, São Paulo, Brazil; ${ }^{\mathrm{P}}$ Department of Obstetrics and Gynecology, St. Mary's Hospital, London, UK; ${ }^{\mathrm{a}}$ Department of Urology, Päijät-Häme Central Hospital, Lahti, Finland; ${ }^{\mathrm{r}}$ Department of Obstetrics and Gynecology, South Karelia Central Hospital, Lappeenranta, Finland; ' ${ }^{\mathrm{s}}$ Michael G. DeGroote Institute for Pain Research and Care, McMaster University, Hamilton, Canada; ${ }^{\mathrm{t} C h i n e s e}$ Cochrane Centre, West China Hospital, Sichuan University, Chengdu, China; ${ }^{\mathrm{u}}$ Department of Clinical Epidemiology and Biostatistics, McMaster University, Hamilton, Ontario, Canada; ${ }^{\mathrm{v}}$ Department of Medicine, McMaster University, Hamilton, Ontario, Canada; ${ }^{\mathrm{w}}$ Departments of Urology and Public Health, University of Helsinki and Helsinki University Hospital, Helsinki, Finland
\end{abstract}

\section{Article info}

Article history:

Accepted January 24, 2016

Associate Editor:

James Catto

Keywords:

Cesarean section

Vaginal delivery

Vacuum

\begin{abstract}
Context: Stress urinary incontinence (SUI) and urgency urinary incontinence (UUI) are associated with physical and psychological morbidity, and large societal costs. The longterm effects of delivery modes on each kind of incontinence remain uncertain. Objective: To investigate the long-term impact of delivery mode on SUI and UUI. Evidence acquisition: We searched Medline, Scopus, CINAHL, and relevant major conference abstracts up to October 31, 2014, including any observational study with adjusted analyses or any randomized trial addressing the association between delivery mode and SUI or UUI $\geq 1 \mathrm{yr}$ after delivery. Two reviewers extracted data, including incidence/prevalence of SUI and UUI by delivery modes, and assessed risk of bias. Evidence synthesis: Pooled estimates from 15 eligible studies demonstrated an increased risk of SUI after vaginal delivery versus cesarean section (adjusted odds ratio [aOR]: 1.85 ; $95 \%$ confidence interval [CI], 1.56-2.19; $\mathrm{I}^{2}=57 \%$; risk difference: $8.2 \%$ ).
\end{abstract}

\footnotetext{
* Corresponding author at: Department of Urology, University of Helsinki and Helsinki University Hospital, Haartmaninkatu 4, 00029 Helsinki, Finland. Tel. +358 505250971.

E-mail address: kari.tikkinen@gmail.com (Kari A.O. Tikkinen).
}

http://dx.doi.org/10.1016/j.eururo.2016.01.037

0302-2838/C 2016 European Association of Urology. Published by Elsevier B.V. This is an open access article under the CC BY license (http://creativecommons.org/licenses/by/4.0/). 
Forceps

Instrumental delivery

Stress urinary incontinence

Urgency urinary incontinence

Systematic review
Metaregression demonstrated a larger effect of vaginal delivery among younger women $(p=0.005)$. Four studies suggested no difference in the risk of SUI between spontaneous vaginal and instrumental delivery (aOR: $1.11 ; 95 \% \mathrm{CI}, 0.84-1.45 ; \mathrm{I}^{2}=50 \%$ ). Eight studies suggested an elevated risk of UUI after vaginal delivery versus cesarean section (aOR: 1.30; 95\% CI, 1.02-1.65; $\mathrm{I}^{2}=37 \%$; risk difference: $2.6 \%$ ).

Conclusions: Compared with cesarean section, vaginal delivery is associated with an almost twofold increase in the risk of long-term SUI, with an absolute increase of $8 \%$, and an effect that is largest in younger women. There is also an increased risk of UUI, with an absolute increase of approximately $3 \%$.

Patient summary: In this systematic review we looked for the long-term effects of childbirth on urinary leakage. We found that vaginal delivery is associated with an almost twofold increase in the risk of developing leakage with exertion, compared with cesarean section, with a smaller effect on leakage in association with urgency.

(C) 2016 European Association of Urology. Published by Elsevier B.V. This is an open access article under the CC BY license (http://creativecommons.org/licenses/by/4.0/).

\section{Introduction}

Stress urinary incontinence (SUI) is defined as the involuntary loss of urine on effort or physical exertion, or on sneezing or coughing. Urgency urinary incontinence (UUI) is defined as involuntary loss of urine associated with a sudden and compelling desire to pass urine [1]. Both from the population perspective and from an individual perspective, SUI and UUI are the most burdensome and bothersome of all urinary symptoms in women [2]. SUI and UUI are associated with substantial physical and psychological morbidity, and large societal costs [3,4]. Established risk factors for urinary incontinence include age and body mass index (BMI) [5]; the prevalence of these conditions is therefore likely to increase with future demographic changes.

Although advances in treatment during the last two decades have decreased morbidity, primary prevention of long-term SUI and UUI remains highly desirable. Mode of delivery is one potentially modifiable risk factor. Vaginal childbirth is known to have major impacts on the pelvic floor, weakening bladder neck support [6] and compromising innervation [7]. Cesarean delivery, particularly prelabor cesarean, is believed to offer substantial protection against such pelvic floor trauma; in contrast, assisted vaginal delivery, with vacuum or forceps, is believed to carry increased risks of trauma. The World Health Organization statement on caesarean section rates recommends that the ideal rate for cesarean sections is between $10 \%$ and $15 \%$ [8]. Observed rates, however, vary widely between countries. Although rates are $<10 \%$ in most low-income countries [9], middle- and high-income countries have seen substantial increases since the 1970s. In 2011 rates were $24 \%$ in the United Kingdom [10], 33\% in the United States [11], and 54\% in Brazil [12]. The increasing use of cesarean section has substantial negative public health consequences, including peripartum infection, bleeding, and thrombosis, and it has an impact on future pregnancies [8]. Any positive consequences from the increased use of cesarean have not been well quantified.

An extensive body of evidence from the first year after delivery demonstrates that in this initial postpartum period, rates of SUI are higher in women delivering vaginally than those delivering by cesarean $[13,14]$. The long-term effects of delivery mode, however, are more important to patients than transient postpartum incontinence. Therefore to reach a better understanding of the association between individual delivery modes and the long-term risk of SUI and UUI, we conducted a systematic review and meta-analysis.

\section{Evidence acquisition}

We registered the protocol (PROSPERO 2013: CRD42013006213) and followed the Preferred Reporting Items for Systematic Reviews and Meta-analysis guidance [15].

\subsection{Search strategy}

An experienced research librarian (M.A.) collaborated in planning the search strategy, performed on October 31, 2014, in Medline (1946 to present), Scopus (1995 to present), and CINAHL (1960 to present). We also searched abstracts published from the annual meetings of the International Continence Society and the International Urogynecological Association (1999-2014). The searches were conducted without language restrictions and adapted for each electronic database. The details of searches are available in Supplement 1.

\subsection{Study selection}

We included any randomized trial, cross-sectional, or cohort study that recorded the delivery mode as well as SUI and/or UUI outcome beyond 1 yr after delivery among primi- and multiparous women and provided an analysis comparing at least two delivery modes with SUI and/or UUI. Because previous studies have established prognostic factors for SUI and UUI [16-20], we included only crosssectional or cohort studies with an analysis that adjusted/ matched for at least one of the following: age [3,16], BMI $[17,19,20]$, or parity [18].

Because SUI and UUI have different etiologies [21-23], we excluded studies that reported on incontinence but did not report specifically on either SUI or UUI (eg, “any urinary incontinence"). We also excluded studies that only reported surrogate measures, such as urodynamic testing, cough stress test, or treatment rates. Reasoning that small studies 
are likely to be published only if they show anomalous results, we excluded studies with $<100$ participants. We accepted the definition of SUI and UUI used in each study, recognizing there would be heterogeneity in definitions, provided definitions captured the women's own perception of incontinence.

\subsection{Data extraction and risk of bias assessment}

We used standard methods for screening and data extraction of systematic reviews (details in Supplement 2). For the risk of bias assessments, we evaluated each study according to six criteria: sampling and representativeness of population, assessment of the exposure, assessment of the outcome, presence of the outcome at the start of study, adjustment for confounding, and missing data (Supplementary Table 1). For each criterion, we judged studies to have either a high or low risk of bias. Studies with a high risk of bias for two or more criteria were classified as high risk of bias overall.

\subsection{Data synthesis and analysis}

For our primary analyses, we examined the association between mode of delivery and SUI or UUI. We calculated pooled estimates of adjusted estimates using the DerSimonian-Laird random-effects inverse variance method, and the $\mathrm{I}^{2}$ statistic [24] and Cochran's $\mathrm{Q}$ as indices of heterogeneity. We used prespecified hypotheses to examine heterogeneity using metaregression analysis weighted by the inverse of the variance in a random-effects model. We examined the following variables as potential sources of heterogeneity: age (as continuous variable), parity (as continuous variable), risk of bias (low vs high), composition of vaginal delivery group (including women delivering only ever by vaginal routes vs including women with both vaginal and cesarean deliveries), and the case definition of SUI or UUI (inclusive mild incontinence definitions vs restrictive severe definitions). We had prespecified hypotheses that effect sizes would be smaller for samples of older women, samples with higher parity, low risk of bias studies, mixed modes of delivery, and studies using a lower threshold (less severe symptoms) in their case definitions. We conducted a single sensitivity analysis including a randomized trial omitted from the primary analysis because of large crossover and concerns regarding applicability (all breech presentations).

To calculate the absolute risk increase of moderate or severe SUI or UUI with vaginal birth, we estimated the absolute risk of SUI or UUI after cesarean section using two large population-based studies [25,26]: $12.2 \%$ for moderate or severe SUI and $10.1 \%$ for moderate or severe UUI after any cesarean section, and $5.0 \%$ for SUI after elective cesarean section, and then used the odds ratio (OR) to calculate the absolute risk increase with vaginal delivery [27].

When primary papers had missing confidence interval (CI) information (ie, providing ORs and $p$ values but not CIs), we calculated the CIs (further information on data analysis in Supplement 3). Meta-analyses were performed using metan [28] and metareg in Stata v12.1 (StataCorp, College Station, TX, USA). We used the Harbord test to detect publication bias.

\section{Evidence synthesis}

\subsection{Literature search and study characteristics}

Our search yielded 3487 potentially relevant reports. After screening titles and abstracts, we retrieved 179 reports for full-text screening, of which 18 proved eligible. Of these 18 , we did not include two studies in meta-analyses: a largescale multicenter randomized trial of planned cesarean versus planned vaginal delivery due to low generalizability because it only included women with fetuses with breech presentations [29-31]; and a small cohort study [32] that combined spontaneous vaginal delivery and cesarean during labor and compared with vacuum or forceps. Of 16 studies included [5,25,26,33-47], 8 addressed the impact of delivery mode on SUI, 7 on both SUI and UUI, and 1 on UUI (Tables 1 and 2; Fig. 1). In these studies we identified 11 different comparisons between delivery modes assessing risk of SUI and 5 different comparisons assessing risk of UUI (Supplementary Fig. 1). The most common comparison was any vaginal delivery (including studies with spontaneous vaginal delivery only, vaginal delivery only, or at least one vaginal delivery) versus cesarean section (15 studies with 45659 women for SUI and 8 studies with 49623 women for UUI) for both SUI and UUI, followed by instrumental delivery versus spontaneous vaginal delivery for SUI (4 studies with 7417 women) (Figs. 2-4; Supplementary Fig. 1 and 2).

Table 1 provides a description of the 16 studies. Table 2 provides authors' definitions of SUI and UUI. Three of the studies included only primiparous women $[26,37,46]$. SUI prevalence estimates varied from $9 \%$ to $68 \%$; UUI from $8 \%$ to $27 \%$. Six (37.5\%) of the 16 authors confirmed the accuracy of

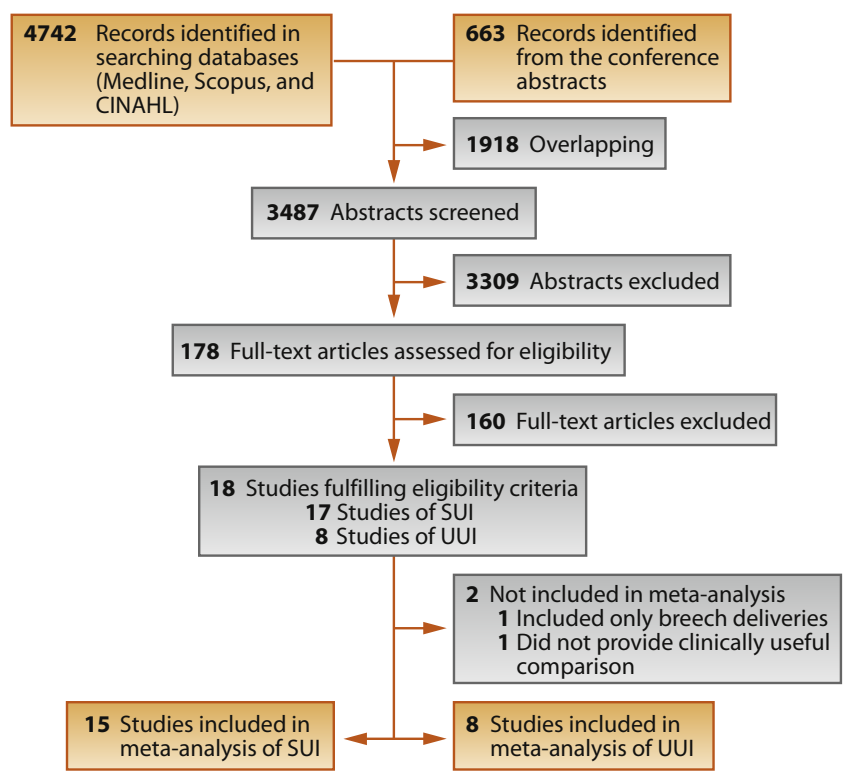

Fig. 1 - Flowchart outlining the literature search and article evaluation process.

SUI = stress urinary incontinence; $\mathrm{UUI}$ = urgency urinary incontinence. 
Table 1 - Characteristics of the 16 eligible studies

\begin{tabular}{|c|c|c|c|c|c|c|c|}
\hline Study & $\begin{array}{c}\text { Analyzed } \\
\text { participants, } n\end{array}$ & $\begin{array}{l}\text { Year(s) data } \\
\text { collected }\end{array}$ & Sampling frame & Type of survey & Specific inclusion criteria & $\begin{array}{c}\text { Age, yr, } \\
\text { mean (range) }\end{array}$ & $\begin{array}{l}\text { Follow-up } \\
\text { time } \\
\text { postpartum }\end{array}$ \\
\hline Altman et al [35] & 395 & 2004-2005 & 1 hospital in Sweden & Mailed questionnaire & $\begin{array}{l}\text { Cases: Women with first birth } \\
\text { vaginal 1995, and all subsequent } \\
\text { deliveries vaginal. Control group: } \\
\text { primiparous women with cesarean } \\
\text { September 1994-December } 1995\end{array}$ & $40(19-46)$ & $10 \mathrm{yr}$ \\
\hline El-Azab et al [36] & 1652 & Not reported & Living in upper Egypt & In person & Women $\geq 20 \mathrm{yr}$ of age & Not reported & Unclear \\
\hline Fritel et al [37] & 307 & 2000 & 2 hospitals in France & Mailed questionnaire & $\begin{array}{l}\text { Primiparous women, with } \\
\text { singleton, vertex, nonpremature } \\
\text { birth } 1996\end{array}$ & $33(21-51)$ & $4 \mathrm{yr}$ \\
\hline Fritel et al [38] & 2625 & 1990-1996 & $\begin{array}{l}\text { Employed by the French } \\
\text { national power company }\end{array}$ & Mailed questionnaire & & $55(50-62)$ & Unclear \\
\hline Goldberg et al [39] & 733 & 2001 & $\begin{array}{l}\text { Participants of the National } \\
\text { Organization of Mothers of } \\
\text { Twins Clubs, USA }\end{array}$ & Given questionnaire & Mothers of multiples & $37(22-75)$ & Unclear \\
\hline Goldberg et al [5] & 341 & 2003-2004 & $\begin{array}{l}\text { Annual gathering of the Twins } \\
\text { Days Festival, USA }\end{array}$ & Given questionnaire & Identical twins & $47(15-85)$ & Unclear \\
\hline Gyhagen et al [26] & 5118 & 2008 & $\begin{array}{l}\text { National birth registry in } \\
\text { Sweden }\end{array}$ & Mailed questionnaire & $\begin{array}{l}\text { Primiparae women with birth } \\
\text { between } 1985 \text { and } 1988\end{array}$ & 53 (not reported) & At least $20 \mathrm{yr}$ \\
\hline Handa et al $[33,34]^{a}$ & $1011 / 449$ & 2008- & 1 US hospital & Given questionnaire & $\begin{array}{l}\text { Women with first birth (singleton, } \\
\text { nonpremature) } 5-10 \text { yr before } \\
\text { enrollment }\end{array}$ & $40^{\mathrm{b}}(23-54)$ & $5-10 \mathrm{yr}$ \\
\hline Handa et al $[40]^{a}$ & 1481 & $2008-2013$ & 1 US hospital & Given questionnaire & $\begin{array}{l}\text { Women with singleton, } \\
\text { nonpremature delivery }\end{array}$ & $38^{c}($ not reported $)$ & $5-12 \mathrm{yr}$ \\
\hline Kepenekci et al [41] & 4002 & $2005-2007$ & $\begin{array}{l}6 \text { different family medicine } \\
\text { centers in Turkey }\end{array}$ & $\begin{array}{l}\text { Questionnaire administered by } \\
\text { trained staff }\end{array}$ & $\begin{array}{l}\text { Women accompanying or } \\
\text { supporting a patient }^{\mathrm{d}}\end{array}$ & $41(15-86)$ & Unclear \\
\hline Lukacz et al [25] & 4103 & 2004-2005 & $\begin{array}{l}\text { Kaiser Permanente Southern } \\
\text { California medical program, USA }\end{array}$ & Mailed questionnaire & $\begin{array}{l}\text { Women from } 4 \text { different age groups } \\
(25-39,40-54,55-69,70-84 \mathrm{yr})\end{array}$ & $57(25-84)$ & Unclear \\
\hline Manonai et al [42] & 1126 & 2003-2004 & $\begin{array}{l}\text { Population-based study in one } \\
\text { province in Thailand }\end{array}$ & $\begin{array}{l}\text { Questionnaire administered by } \\
\text { trained staff }\end{array}$ & & $39(15-100)$ & Unclear \\
\hline Rortveit et al [43] & 15307 & 1995-1997 & $\begin{array}{l}\text { Population-based study in one } \\
\text { county in Norway }\end{array}$ & Self-administered questionnaire & & $38(20-64)$ & Unclear \\
\hline Singh et al [44] & 3000 & 2005-2007 & 1 hospital in India & $\begin{array}{l}\text { Questionnaire administered by a } \\
\text { doctor }\end{array}$ & $\begin{array}{l}\text { Women attending obstetrics/ } \\
\text { gynecology clinic }\end{array}$ & $40^{\mathrm{b}}$ (unclear) & Unclear \\
\hline Song et al [45] & 5392 & 2002 & $\begin{array}{l}\text { Population-based study in one } \\
\text { community in China }\end{array}$ & Mailed questionnaire & & $40(18-87)$ & Unclear \\
\hline Yang et al [46] & 548 & 2001-2002 & One hospital in China & Telephone interview & $\begin{array}{l}\text { Primiparae women with birth } \\
\text { between } 2001 \text { and } 2002\end{array}$ & 29 (not reported) & Unclear \\
\hline Zhu et al [47] & 19024 & 2006 & $\begin{array}{l}\text { Population-based study in six } \\
\text { provinces in China }\end{array}$ & $\begin{array}{l}\text { Questionnaire administered by a } \\
\text { doctor }\end{array}$ & & 45 (20-99) & Unclear \\
\hline \multicolumn{8}{|c|}{$\begin{array}{l}\text { Of the } 16 \text { studies included, } 8 \text { addressed the impact of delivery mode on SUI }[5,25,33,34,37-40,45,46], 7 \text { on both SUI and UUI }[26,35,36,41-44] \text {, and } 1 \text { on UUI [47]. } \\
\text { a From the same study, two eligible articles [33,34] using the baseline data and one article [40] using the prospective data have been published. } \\
\text { b Median age. }\end{array}$} \\
\hline
\end{tabular}


Table 2 - Stress urinary incontinence and urgency urinary incontinence assessment in the 16 eligible studies

\begin{tabular}{|c|c|c|c|c|c|}
\hline Study & $\begin{array}{l}\text { Validated } \\
\text { questionnaire } \\
\text { used }\end{array}$ & $\begin{array}{l}\text { Type of urinary } \\
\text { incontinence } \\
\text { assessed }\end{array}$ & Specific SUI question used & $\begin{array}{l}\text { Specific UUI question } \\
\text { used }\end{array}$ & $\begin{array}{l}\text { Response options/ } \\
\text { Definition of normal- } \\
\text { abnormal }^{\mathrm{a}}\end{array}$ \\
\hline Altman et al [35] & Modeled CCI Score & $\begin{array}{l}\text { Stress } \\
\text { and urgency }\end{array}$ & $\begin{array}{l}\text { Do you experience involuntary } \\
\text { loss of urine at physical } \\
\text { activities? }\end{array}$ & $\begin{array}{l}\text { Do you experience } \\
\text { sudden urges to void } \\
\text { urine that are followed by } \\
\text { involuntary loss of urine? }\end{array}$ & $\begin{array}{l}\text { No/Less than once/ } \\
\text { week-More than once/ } \\
\text { week-Daily }\end{array}$ \\
\hline El-Azab et al [36] & $\begin{array}{l}\text { UDI-6, Arabic } \\
\text { version }\end{array}$ & $\begin{array}{l}\text { Stress } \\
\text { and urgency }\end{array}$ & $\begin{array}{l}\text { Do you experience, and, if so, } \\
\text { how much are you bothered by } \\
\text { urine leakage related to physical } \\
\text { activity, coughing, or sneezing? }\end{array}$ & $\begin{array}{l}\text { Do you experience, and, if } \\
\text { so, how much are you } \\
\text { bothered by urine leakage } \\
\text { related to the feeling of } \\
\text { urgency? }\end{array}$ & $\begin{array}{l}\text { Not at all/Slightly- } \\
\text { Moderately-Greatly }\end{array}$ \\
\hline Fritel et al [37] & $\begin{array}{l}\text { BFLUTS, French } \\
\text { version }^{c}\end{array}$ & $\begin{array}{l}\text { Stress } \\
\text { (and urgency) }{ }^{\mathrm{d}}\end{array}$ & $\begin{array}{l}\text { Does urine leak, when you are } \\
\text { physically active, cough, or } \\
\text { sneeze? }\end{array}$ & & $\begin{array}{l}\text { Never/Occasionally- } \\
\text { Sometimes-Often-All } \\
\text { the time }\end{array}$ \\
\hline Fritel et al [38] & $\begin{array}{l}\text { BFLUTS, French } \\
\text { version }\end{array}$ & Stress & $\begin{array}{l}\text { Does urine leak, when you are } \\
\text { physically active, cough, or } \\
\text { sneeze? }\end{array}$ & & $\begin{array}{l}\text { Never/Occasionally- } \\
\text { Sometimes-Often-All } \\
\text { the time }\end{array}$ \\
\hline Goldberg et al [39] & PFDI and IIQ, UDI & $\begin{array}{l}\text { Stress } \\
\text { (and urgency) }{ }^{d}\end{array}$ & $\begin{array}{l}\text { Do you leak urine with } \\
\text { coughing, straining, laughing, } \\
\text { physical activity, or exercise? }\end{array}$ & & $\begin{array}{l}\text { Not at all/Slightly- } \\
\text { Moderately-Greatly }\end{array}$ \\
\hline Goldberg et al [5] & PFDI and IIQ & $\begin{array}{l}\text { Stress } \\
\text { (and urgency) }{ }^{\mathrm{d}}\end{array}$ & $\begin{array}{l}\text { Do you leak urine with } \\
\text { coughing, straining, laughing, } \\
\text { physical activity, or exercise? }\end{array}$ & & $\begin{array}{l}\text { Not at all/Slightly- } \\
\text { Moderately-Greatly }\end{array}$ \\
\hline Gyhagen et al [26] & $\begin{array}{l}\text { Sandvik } \\
\text { questionnaire }\end{array}$ & $\begin{array}{l}\text { Stress } \\
\text { and urgency }\end{array}$ & $\begin{array}{l}\text { Do you have involuntary loss of } \\
\text { urine in connection with } \\
\text { coughing, sneezing, laughing, } \\
\text { lifting heavy items? }^{\mathrm{c}}\end{array}$ & $\begin{array}{l}\text { Do you have involuntary } \\
\text { loss of urine in } \\
\text { connection with sudden } \\
\text { and strong urge to void? }\end{array}$ & $\begin{array}{l}\text { Not at all/Slight- } \\
\text { Moderate-Severe }\end{array}$ \\
\hline Handa et al $[33,34,40]$ & EPIQ & $\begin{array}{l}\text { Stress } \\
\text { (and urgency) }{ }^{\mathrm{d}}\end{array}$ & $\begin{array}{l}\text { Do you experience urine leakage } \\
\text { related to activity, coughing, or } \\
\text { sneezing? }\end{array}$ & & No/Yes \\
\hline Kepenekci et al [41] & UDI & $\begin{array}{l}\text { Stress } \\
\text { and urgency }\end{array}$ & $\begin{array}{l}\text { Do you experience, and if so, } \\
\text { how much are you bothered by } \\
\text { leakage related to physical } \\
\text { activity, coughing, or sneezing? }\end{array}$ & $\begin{array}{l}\text { Do you experience, and if } \\
\text { so, how much are you } \\
\text { bothered by leakage } \\
\text { related to feeling of } \\
\text { urgency? }\end{array}$ & $\begin{array}{l}\text { Not at all/Slightly- } \\
\text { Moderately-Greatly }\end{array}$ \\
\hline Lukacz et al [25] & EPIQ & $\begin{array}{l}\text { Stress } \\
\text { (and urgency) }^{\mathrm{d}}\end{array}$ & $\begin{array}{l}\text { Do you experience urine leakage } \\
\text { related to activity, coughing, or } \\
\text { sneezing? }\end{array}$ & & No/Yes \\
\hline Manonai et al [42] & & $\begin{array}{l}\text { Stress } \\
\text { and urgency }\end{array}$ & Not reported & Not reported & \\
\hline Rortveit et al [43] & $\begin{array}{l}\text { Sandvik } \\
\text { questionnaire }\end{array}$ & $\begin{array}{l}\text { Stress } \\
\text { and urgency }\end{array}$ & $\begin{array}{l}\text { Do you leak when coughing, } \\
\text { sneezing, laughing, lifting heavy } \\
\text { items? }\end{array}$ & $\begin{array}{l}\text { Is leakage accompanied } \\
\text { with a sudden and strong } \\
\text { urge to void? }\end{array}$ & $\begin{array}{l}\text { Not at all/Slight- } \\
\text { Moderate-Severe }\end{array}$ \\
\hline Singh et al [44] & & $\begin{array}{l}\text { Stress } \\
\text { and urgency }\end{array}$ & $\begin{array}{l}\text { Screening question: "Do you } \\
\text { have complaint of urinary } \\
\text { leakage?" was used. } \\
\text { Subsequently, specific } \\
\text { incontinence questions were } \\
\text { used but remain unclear }\end{array}$ & $\begin{array}{l}\text { Screening question: "Do } \\
\text { you have complaint of } \\
\text { urinary leakage?" was } \\
\text { used. Subsequently, } \\
\text { specific incontinence } \\
\text { questions were used but } \\
\text { remain unclear }\end{array}$ & No/Yes \\
\hline Song et al [45] & & Stress & $\begin{array}{l}\text { Do you experience urine leakage } \\
\text { related to activity, coughing, or } \\
\text { sneezing? }\end{array}$ & & $\begin{array}{l}\text { No/Yes } \\
\text { Severity: 0-5 }\end{array}$ \\
\hline Yang et al [46] & $\begin{array}{l}\text { Modified from } \\
\text { BFLUTS, } \\
\text { Chinese version }\end{array}$ & $\begin{array}{l}\text { Stress } \\
\text { (and urgency) }{ }^{\mathrm{d}}\end{array}$ & $\begin{array}{l}\text { Do you experience urine leakage } \\
\text { related to activity, coughing, or } \\
\text { sneezing? }\end{array}$ & & $\begin{array}{l}\text { Never/Occasionally- } \\
\text { Sometimes/often-All } \\
\text { the time }\end{array}$ \\
\hline Zhu et al [47] & $\begin{array}{l}\text { BFLUTS, Chinese } \\
\text { version }\end{array}$ & $\begin{array}{l}\text { Urgency } \\
\text { (and stress) }^{\mathrm{e}}\end{array}$ & & $\begin{array}{l}\text { Does urine leak before } \\
\text { you can get to the toilet? }\end{array}$ & $\begin{array}{l}\text { Never/Occasionally- } \\
\text { Sometimes/often-All } \\
\text { the time }\end{array}$ \\
\hline \multicolumn{6}{|c|}{$\begin{array}{l}\text { BFLUTS = Bristol Female Lower Urinary Tract Symptoms Questionnaire; CCI Score = Clevel } \\
\text { Incontinence Questionnaire; International Consultation on Incontinence Questionnaire-F } \\
\text { Questionnaire; PFDI = Pelvic Floor Distress Inventory; SUI = stress urinary incontinence; UI } \\
\text { a Cut-off point (threshold) used for normal versus abnormal symptom occurrence. Respor } \\
\text { studies used the same response options for both SUI and UUI. } \\
\text { b Specific question not provided in publication. } \\
\text { c Information provided by the author, not in the published reference. } \\
\text { d Information regarding UUI was also measured, but effect estimates were not reported. } \\
\text { e Information regarding SUI was also measured, but effect estimates were not reported. }\end{array}$} \\
\hline
\end{tabular}




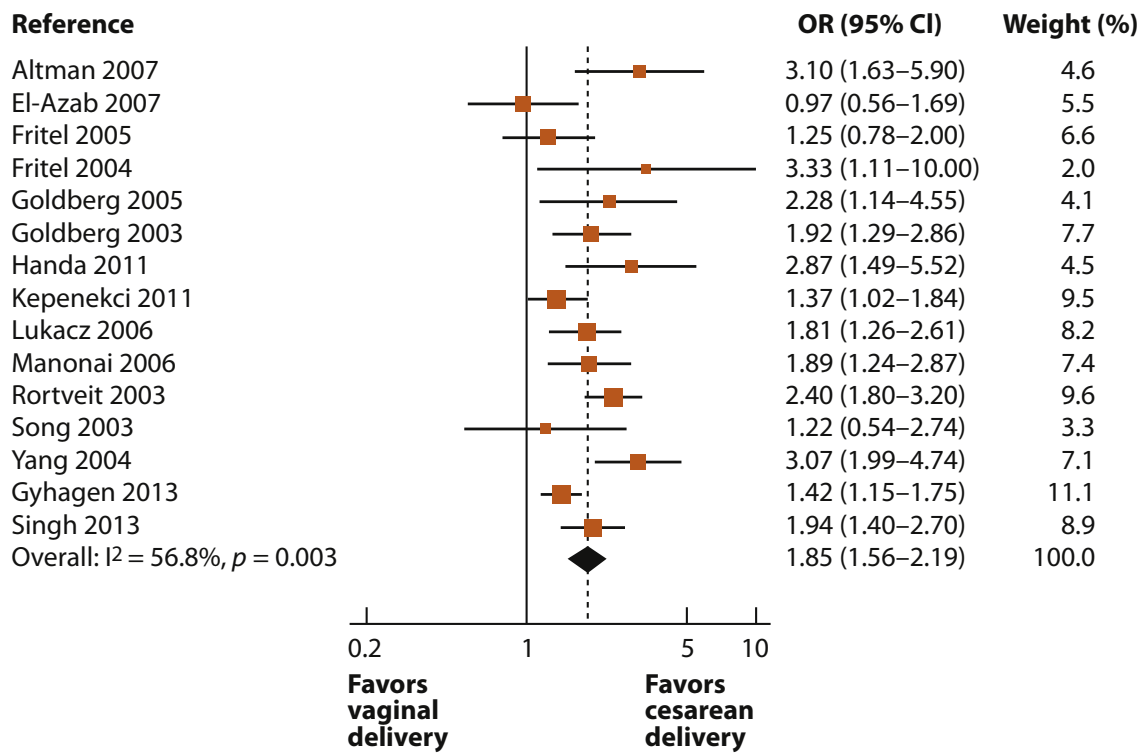

Fig. 2 - Forest plot showing risk of stress urinary incontinence between vaginal delivery and cesarean section. $\mathrm{CI}=$ confidence interval; $\mathrm{OR}=$ odds ratio.

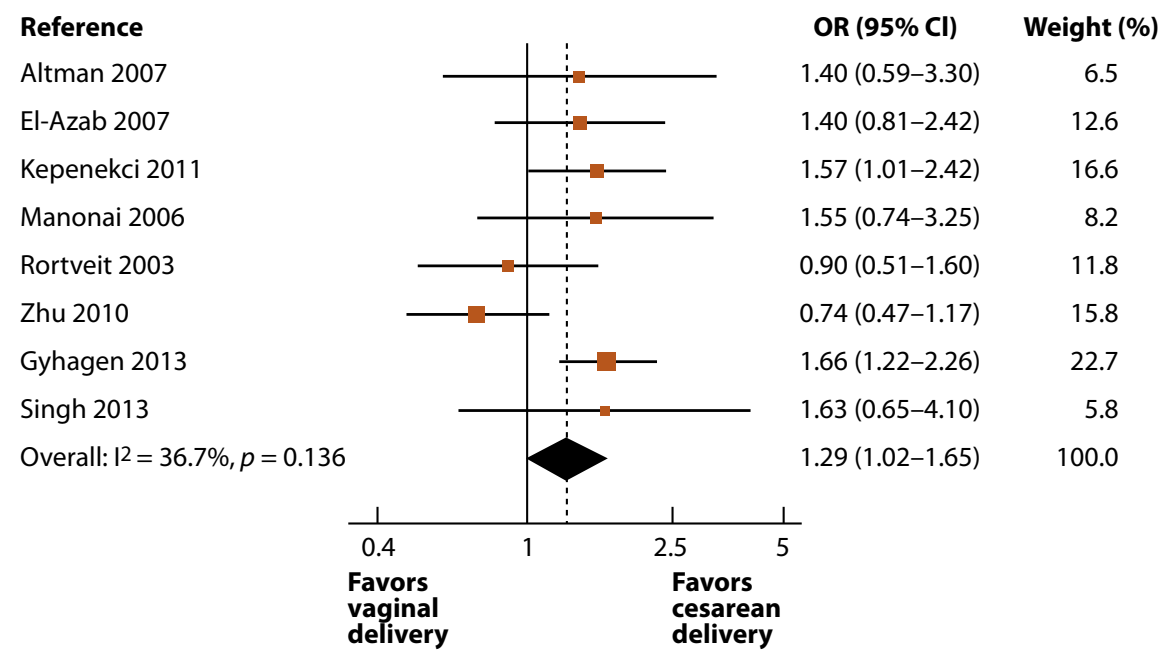

Fig. 3 - Forest plot showing risk of urgency urinary incontinence between vaginal delivery and cesarean section. $\mathrm{CI}=$ confidence interval; $\mathrm{OR}=$ odds ratio.

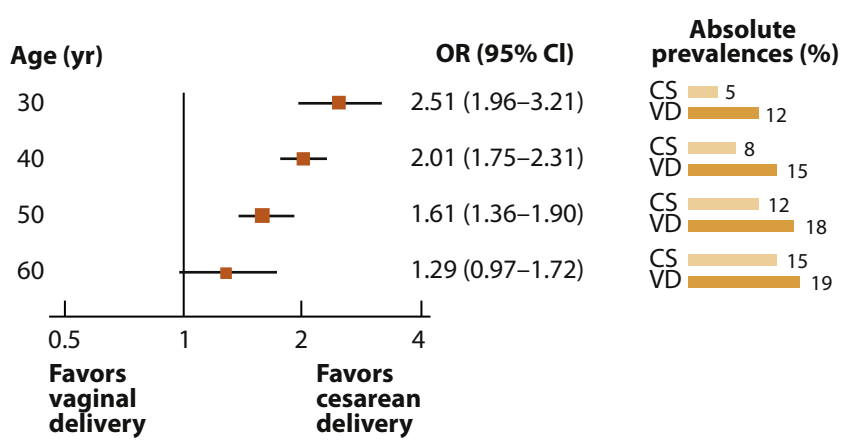

Fig. 4 - Relative and absolute risk of stress urinary incontinence between vaginal delivery and cesarean section by age group. $\mathrm{CI}=$ confidence interval; $\mathrm{CS}=$ cesarean section; $\mathrm{OR}=$ odds ratio; VD = vaginal delivery . our consensus data extraction [25,26,34,37,42,47]; four (25\%) corrected some errors or provided additional information $[37,38,41,43]$; six (37.5\%) were unable to assist with our requests for data checks and clarifications [5,35,39,44-46].

We identified only two prospective studies $[30,40]$. One randomized trial [29-31] included only women with fetuses presenting in breech position. In this study there was a significant crossover between groups: for women randomized to planned cesarean section group, 941 (90.4\%) delivered by cesarean section, but for those randomized to the planned vaginal delivery group, only 591 (56.7\%) were delivered vaginally. The study assessed rates of SUI for the "previous $7 \mathrm{~d}$ " at $3 \mathrm{mo}$, and for the "previous 3-6 mo" at $2 \mathrm{yr}$, which likely explains the observed higher rates of SUI at $2 \mathrm{yr}$ compared with $3 \mathrm{mo}$. At 3 mo postpartum, the authors noted a lower rate of SUI among women assigned to 
planned cesarean section compared with planned vaginal delivery $(4.5 \%$ vs $7.3 \% ; p=0.02)$. At $2 \mathrm{yr}$, the difference between groups was no longer significant ( $17.8 \%$ vs $21.8 \%$; $p=0.14$ ). Inclusion of this trial in a sensitivity analysis did not materially change the results (adjusted odds ratio [aOR]: 1.78; 95\% CI, 1.51-2.10; risk difference: 7.6\%).

The other prospective study [40] reported longitudinal changes of pelvic floor disorders for parous women with and without a history of vaginal delivery. This study recruited women at 5-10 yr after a first birth to annual follow-up over $5 \mathrm{yr}$. At the baseline assessment (no difference in maternal age or in time from first delivery to study enrollment between groups), the prevalence of SUI was $54 \%$ in vaginal versus $20 \%$ in cesarean delivery; for UUI, prevalence was $17 \%$ in vaginal and $7 \%$ in cesarean delivery. We used cross-sectional analyses of these baseline data $[33,34]$ in our meta-analyses. The longitudinal data collection demonstrated that differences between vaginal and cesarean section diminished over time from delivery.

\subsection{Risk of bias}

In all studies, women undergoing different delivery modes were drawn from the same database, over the same time frame, and we judged the assessment of mode of delivery exposure as accurate. Eight studies nevertheless met criteria for high risk of bias (Supplement 4 and Supplementary Fig. 3). Thirteen studies (81\%) had little missing data or used self-reported validated questionnaires or another method with demonstrated validity. Twelve studies (75\%) adjusted/matched for all the most important confounders (age, BMI, parity). No study collected information regarding SUI or UUI before delivery.

\subsection{Impact of delivery mode on stress and urgency urinary incontinence}

In the pooled analysis (15 studies: 7 low and 8 high risk of bias), the odds of reporting SUI was almost double after any vaginal delivery (spontaneous or assisted) (aOR: 1.85; 95\% CI, 1.56-2.19; heterogeneity: $p=0.003 ; \mathrm{I}^{2}=57 \%$; risk difference: $8.2 \%$ ) compared with any cesarean section. All studies but one [36] suggested an increased risk, and in 12 of 15 studies the CI excluded no effect (Fig. 2). When comparing elective cesarean with the decision made before the onset of labor only, two (both high risk of bias) studies $[20,28]$ reported a risk of SUI over three times higher with vaginal delivery (aOR: 3.53 ; 95\% CI, 2.55-4.90; heterogeneity: $p=0.84 ; \mathrm{I}^{2}=0 \%$; risk difference: $10.7 \%$ ).

The pooled analysis (four studies, two low and two high risk of bias) demonstrated no significant difference in SUI between instrumental delivery, including vacuum and forceps, and spontaneous vaginal delivery (aOR: 1.11; 95\% CI, 0.84-1.45; heterogeneity: $p=0.11 ; \mathrm{I}^{2}=50 \%$ ) (Supplementary Fig. 2). The results were similar when comparing vacuum with spontaneous vaginal delivery (two studies, both high risk of bias; aOR: $1.10 ; 95 \% \mathrm{CI}, 0.80-1.51$; heterogeneity: $\left.p=0.60 ; \mathrm{I}^{2}=0 \%\right)[31,38]$ or forceps to spontaneous vaginal delivery (three studies, two low and one high risk of bias; aOR: 1.16; $95 \% \mathrm{CI}, 0.71-1.89$; heterogeneity: $\left.p=0.06, \mathrm{I}^{2}=65 \%\right)[5,34,38]$.

The pooled analysis (eight studies, three low and five high risk of bias) demonstrated that the risk of UUI was modestly increased after vaginal delivery when compared with cesarean delivery (aOR: 1.30; 95\% CI, 1.02-1.65; heterogeneity: $p=0.14 ; \mathrm{I}^{2}=37 \%$; risk difference: $2.6 \%$ ) (Fig. 3). No study reported the impact of elective cesarean only versus vaginal delivery on UUI.

One low risk of bias study [48] compared vacuum deliveries with a combination of spontaneous vaginal deliveries and forceps deliveries (aOR: $0.8 ; 95 \% \mathrm{CI}$, 0.6-1.0 for SUI; and aOR: 1.2; 95\% CI, 0.7-2.2 for UUI), and forceps deliveries to a combination of spontaneous vaginal deliveries and vacuum deliveries (aOR: $0.9 ; 95 \% \mathrm{CI}, 0.7-1.1$ for SUI; and aOR: $0.8 ; 95 \% \mathrm{CI}, 0.4-1.5$ for UUI). One high risk of bias study [41] compared the risk of UUI between vacuum and spontaneous vaginal delivery (aOR: 1.03; 95\% CI, 0.64-1.67 in our reanalysis adjusted for age and parity using data provided by authors).

One high risk of bias study [33] reported no significant differences between cesarean in the first stage of labor versus elective cesarean (aOR: 0.88 ; $95 \% \mathrm{CI}, 0.40-1.91$ ) or cesarean in the second stage of labor versus elective cesarean (aOR: 1.30 ; 95\% CI, 0.57-2.95) but had more than a fourfold risk of SUI (aOR: 4.45; 95\% CI, 2.14-9.27) in instrumental delivery versus elective cesarean.

\subsection{Variability across studies}

Mean age and parity of study populations, case definition of SUI and UUI, definition of vaginal delivery groups, risk of bias, and survey methods varied across studies (Tables 1 and 2). In the 15 studies addressing the association between vaginal versus cesarean delivery and SUI, in univariable metaregressions we found that the mean sample age at ascertainment of outcome $(p=0.005)$ modified the effect of delivery mode on SUI (older age, smaller effect). Other hypothesized effect modifiers were nonsignificant in univariable metaregression. Based on the results of the metaregression, we were able to calculate the estimated OR for the association between delivery mode and SUI, at various levels of mean sample age (Fig. 4). Ascertained at age 30 , the OR associated with vaginal delivery was $2.51(95 \% \mathrm{CI}, 1.96-3.21)$; ascertained at age 60 , the OR was 1.29 ( $95 \% \mathrm{CI}, 0.97-1.72$ ).

In addressing the risk of UUI between vaginal delivery and cesarean, the small number of studies limited the power of the metaregressions. We did not identify statistically significant sources of heterogeneity in effect size for these meta-analyses. There was no evidence of publication bias, either on visual inspection of funnel plots (Supplementary Fig. 4) or when applying the Harbord test.

\subsection{Discussion}

This systematic review examining the association between delivery mode and the presence of SUI and UUI $>1 \mathrm{yr}$ after delivery identified 11 different comparisons between 
delivery modes assessing risk of SUI and 5 different comparisons assessing risk of UUI. Meta-analysis of data from 15 cross-sectional studies demonstrated an almost twofold increase in the risk of developing long-term SUI, an absolute increase of approximately $8 \%$ in moderate or severe SUI when comparing any vaginal delivery with cesarean section. The impact was age dependent and decreased in cohorts of older women. Ascertained at age 30 , the OR associated with vaginal delivery versus cesarean was 2.51; ascertained at age 60 , the OR was 1.29 . This difference in gradient reflects the increasing incidence of incontinence for reasons other than mode of delivery as women age.

When SUI was compared with specifically elective cesarean, the risk was over three times higher, an absolute increase of $>10 \%$. Meta-analysis also showed a small increased risk of UUI after vaginal delivery compared with cesarean, an absolute increase of approximately $3 \%$. Results showed no difference in the risk of SUI when comparing instrumental vaginal delivery and spontaneous vaginal delivery.

Aside from one randomized trial [29-31] including only breech presentations, only one optimally adjusted longitudinal study addressed the question of interest [40]. In this study, symptoms related to SUI and UUI were more common and of greater severity after vaginal than cesarean birth. Consistent with results in our metaregression of age on effect size, SUI symptom differences between these two groups decreased with increasing time from childbirth.

\subsection{Strengths and limitations}

The strengths of our study include the comprehensive search without language restrictions, the duplicate assessment of eligibility and data abstraction, the appraisal of risk of bias, and the contribution of authors of primary studies to confirmation and clarification of our data abstraction. We used appropriate statistical methods to generate pooled estimates and explored possible sources of heterogeneity, demonstrating that apparent effects of spontaneous vaginal delivery versus cesarean section on SUI decreased with increasing age of assessment of SUI. We have also separately quantified the larger benefit associated with elective prelabor cesarean, compared with any cesarean section (either before or during labor). Finally, we not only estimated relative effects but also provided absolute estimates.

The limitations of our review are largely the weaknesses of the eligible studies. Investigators have conducted only one randomized trial [30] and only one prospective cohort study [40] examining the impact of delivery mode on SUI and UUI. Although there were numerous comparisons between delivery modes assessing the risk of SUI and UUI, it was frequently impossible to compare data quantitatively. In particular, most primary studies combined all cesarean sections, irrespective of timing. We were able to conduct analyses specifically for prelabor cesarean compared with vaginal delivery, but we were not able to compare prelabor cesarean with cesarean after cervical dilatation; nor were we able to compare elective cesarean with planned vaginal delivery (ie, including both vaginal deliveries and cesarean after cervical dilatation). Furthermore, the effect estimates in the analysis comparing instrumental delivery and cesarean section, and elective cesarean and vaginal delivery were imprecise due to lack of statistical power. None of the studies collected information about SUI or UUI before delivery. In addition, 11 studies had unknown follow-up time $[5,25,36,38,39,41,42,44-47]$. However, the median of mean/median ages of the women included in these studies was $>40 \mathrm{yr}$, implying that these studies also examined longterm impact of delivery mode on SUI and UUI.

As in all large-scale studies of incontinence, the included primary studies used self-report of incontinence, rather than diagnoses reached using urodynamics. We consider that self-report of SUI or UUI provides the most patientrelevant outcome. However, symptomatic incontinence may show limited correlation with urodynamic diagnosis, and thus these findings should not be generalized to diagnoses of urodynamic SUI or detrusor overactivity [49].

\subsection{Relation to prior work}

Although previous systematic reviews have demonstrated an increased risk of early postpartum incontinence after vaginal delivery compared with cesarean section $[13,14]$, investigators have not previously conducted a rigorous review of long-term effects. One earlier systematic review focused entirely on the short-term postpartum period and included only studies with follow-up $<1 \mathrm{yr}$ [14], whereas the other one [13] included two appropriately adjusted cross-sectional studies of incontinence beyond the first postpartum year $[37,43]$. In contrast, our own search found 16 studies that could be included in meta-analyses. These much larger pooled analyses have provided more precise estimates of the impact of vaginal delivery compared with cesarean section on SUI.

The potential impact of delivery mode on UUI has received little consideration compared with the impact of delivery mode on SUI [21]. The only available prior review found no statistically significant difference between vaginal delivery and cesarean section [13]. In our much larger pooled analysis of eight studies (including 49623 women), we were able to detect a modest effect size with tight CIs. For the first time, we have also been able to perform a quantitative synthesis of studies of instrumental delivery, finding no impact on SUI.

\subsection{Implications of findings}

Incontinence is very common among women irrespective of delivery history: prevalence estimates vary from $2.8 \%$ to $30.8 \%$ for SUI and from $0.7 \%$ to $19.9 \%$ for UUI [50,51]. Hence potentially increasing use of cesarean section may have beneficial public health consequences from the perspective of pelvic floor health, including decreased need for SUI and pelvic organ prolapse surgery [52,53]. Our results are consistent with those of a Swedish cohort study that reported vaginal deliveries increased surgical treatment 
for incontinence (hazard ratio: 2.9; 95\% CI, 2.4-3.6) compared with women only having cesarean deliveries. The increased risk persisted for $>3$ decades [52]. The estimates provided here may be useful when counseling women about the risk and benefits of different delivery modes. Although we have quantified one benefit of planned cesarean, women and their caregivers must consider other consequences. Planned cesarean section confers an increased risk of neonatal intensive care admission for the baby and a substantially longer hospital stay for the mother [54]. A prior cesarean also carries risks in future pregnancies, including an increased risk of uterine rupture and abnormal placentation [54]. In general, the medicalization of pregnancy associated with planned cesarean may also be undesirable from both individual and societal perspectives [55].

\section{Conclusions}

Our results demonstrate that vaginal delivery is associated with almost double the odds of long-term SUI, an absolute increase of approximately $8 \%$ when compared with cesarean section. The effect is largest in younger women but diminishes with age. The odds of UUI is also increased after vaginal delivery, but the pooled absolute difference is sufficiently small (3\%) that cesarean section rates have only a small impact on UUI at a population level. The available evidence suggests no difference in the odds of SUI, if planned vaginal delivery results in instrumental delivery instead of spontaneous vaginal delivery. These data quantify one important aspect of cesarean section, to help women and their physicians make decisions regarding mode of delivery.

Author contributions: Kari A.O. Tikkinen had full access to all the data in the study and takes responsibility for the integrity of the data and the accuracy of the data analysis.

Study concept and design: Tähtinen, Cartwright, Tikkinen. Acquisition of data: Tähtinen, Cartwright, Tsui, Aaltonen, Aoki, Cárdenas, El Dib, Joronen, Al Juaid, Kalantan, Kochana, Kopec, Lopes, Mirza, Oksjoki, Pesonen, Valpas, Wang, Zhang, Tikkinen.

Analysis and interpretation of data: Tähtinen, Cartwright, Heels-Ansdell, Guyatt, Tikkinen.

Drafting of the manuscript: Tähtinen.

Critical revision of the manuscript for important intellectual content: Tähtinen, Cartwright, Tsui, Aaltonen, Aoki, Cárdenas, El Dib, Joronen, Al Juaid, Kalantan, Kochana, Kopec, Lopes, Mirza, Oksjoki, Pesonen, Valpas, Wang, Zhang, Heels-Ansdell, Guyatt, Tikkinen.

Statistical analysis: Tähtinen, Cartwright, Heels-Ansdell, Guyatt, Tikkinen.

Obtaining funding: Tikkinen.

Administrative, technical, or material support: None.

Supervision: Cartwright, Guyatt, Tikkinen.

Other (specify): None.

Financial disclosures: Kari A.O. Tikkinen certifies that all conflicts of interest, including specific financial interests and relationships and affiliations relevant to the subject matter or materials discussed in the manuscript (eg, employment/affiliation, grants or funding, consultancies, honoraria, stock ownership or options, expert testimony, royalties, or patents filed, received, or pending), are the following: Riikka M.
Tähtinen declares reimbursement from Johnson \& Johnson for attending a scientific meeting. Riikka L. Aaltonen declares reimbursement from Astellas for attending a scientific meeting. Sanna M. Oksjoki declares reimbursement from Ferring for attending a scientific meeting. Jori S. Pesonen declares unrestricted research grants from Pfizer and Ferring, and reimbursement from Astellas and Novartis for attending scientific meetings. Antti Valpas declares reimbursement from Astellas and Pfizer for attending scientific meetings.

Funding/Support and role of the sponsor: This Mode of Delivery and Urinary Leakage (MODULE) project was conducted by the Clinical Urology and Epidemiology (CLUE) Working Group supported by the Academy of Finland (276046), Competitive Research Funding of the Helsinki and Uusimaa Hospital District, Competitive Research Funding of the South Karelia Social and Welfare District, Jane and Aatos Erkko Foundation, and Sigrid Jusélius Foundation. Riikka M. Tähtinen was also financially supported by the Competitive Research Fundings of the Kanta-Häme Central Hospital and Pohjois-Savo Health Care District, and Rufus Cartwright by the UK Medical Research Council. The sponsors had no role in the analysis and interpretation of the data or the manuscript preparation, review, or approval.

Acknowledgments: The authors would like to thank these researchers for checking extracted data for accuracy and/or providing additional information regarding the original studies: Sylvia Botros, Ahmed El-Azab, Xavier Fritel, Maria Gyhagen, Victoria Handa, Diana Kuh, Mehmet Ayhan Kuzu, Limin Liao, Emily Lukacz, Jittima Manonai, Guri Rørtveit, and Lan Zhu. We would also like to thank information specialist Mervi Ahola for advice regarding literature search strategies and Anssi Auvinen for constructive comments on study design and concept.

\section{Appendix A. Supplementary data}

Supplementary data associated with this article can be found, in the online version, at http://dx.doi.org/10.1016/j. eururo.2016.01.037.

\section{References}

[1] Haylen BT, de Ridder D, Freeman RM, et al., International Urogynecological Association; International Continence Society. An International Urogynecological Association (IUGA)/International Continence Society (ICS) joint report on the terminology for female pelvic floor dysfunction. Neurourol Urodyn 2010;29:4-20.

[2] Agarwal A, Eryuzlu LN, Cartwright R, et al. What is the most bothersome lower urinary tract symptom? Individual- and population-level perspectives for both men and women. Eur Urol 2014; 65:1211-7.

[3] Wood LN, Anger JT. Urinary incontinence in women. BMJ 2014; 349:g4531.

[4] Subak LL, Brown JS, Kraus SR, et al., Diagnostic Aspects of Incontinence Study Group. The "costs" of urinary incontinence for women. Obstet Gynecol 2006;107:908-16.

[5] Goldberg RP, Abramov Y, Botros S, et al. Delivery mode is a major environmental determinant of stress urinary incontinence: results of the Evanston-Northwestern twin sisters study. Am J Obstet Gynecol 2005;193:2149-53.

[6] Peschers U, Schaer G, Anthuber C, Delancey JO, Schuessler B. Changes in vesical neck mobility following vaginal delivery. Obstet Gynecol 1996;88:1001-6.

[7] Allen RE, Hosker GL, Smith AR, Warrell DW. Pelvic floor damage and childbirth: a neurophysiological study. Br J Obstet Gynaecol 1990; 97:770-9. 
[8] WHO statement on caesarean section rates. World Health Organization Web site. http://www.who.int/reproductivehealth/ publications/maternal_perinatal_health/cs-statement/en/. Updated April 2015. Accessed June 25, 2015.

[9] The global numbers and costs of additionally needed and unnecessary caesarean sections performed per year: overuse as a barrier to universal coverage. World Health Organization Web site. http://www.who.int/healthsystems/topics/financing/healthreport/ 30C-sectioncosts.pdf. Updated 2010. Accessed April 6, 2015.

[10] European Health for All database. World Health Organization Web site. http://www.euro.who.int/en/data-and-evidence/databases/ european-health-for-all-database-hfa-db. Updated April 2014. Accessed April 6, 2015.

[11] Trends in low-risk cesarean delivery in the United States, 1990-2013. US Department of Health and Human Services Web site. http://www.cdc.gov/nchs/data/nvsr/nvsr63/nvsr63_06. pdf. Updated 2013. Accessed February 10, 2015.

[12] Percentage of cesarean deliveries [in Portugese]. Brazilian Ministry of Health Web site. http://tabnet.datasus.gov.br/cgi/tabcgi.exe? idb2012/f08.def. Updated 2012. Accessed April 6, 2015.

[13] Press J, Klein M, Kaczorowski J, Liston R, von Dadelszen P. Does cesarean section reduce postpartum urinary incontinence? A systematic review. Birth 2007;34:228-37.

[14] Thom D, Rortveit G. Prevalence of postpartum urinary incontinence: a systematic review. Acta Obstet Gynecol Scand 2010;89:1511-22.

[15] Moher D, Liberati A, Tetzlaff J, Altman D. Preferred reporting items for systematic reviews and meta-analyses: the PRISMA statement. J Clin Epidemiol 2009;62:1006-12.

[16] Hannestad YS, Rortveit G, Sandvik H, Hunskaar S. A communitybased epidemiological survey of female urinary incontinence: the Norwegian EPINCONT study. J Clin Epidemiol 2000;53:1150-7.

[17] Subak LL, Richter HE, Hunskaar S. Obesity and urinary incontinence: epidemiology and clinical research update. J Urol 2009;182(Suppl): S2-7.

[18] Rortveit G, Hannestad YS, Daltveit AK, Hunskaar S. Age- and typedependent effects of parity on urinary incontinence: the Norwegian EPINCONT study. Obstet Gynecol 2001;98:1004-10.

[19] Hunskaar S. A systematic review of overweight and obesity as risk factors and targets for clinical intervention for urinary incontinence in women. Neurourol Urodyn 2008;27:749-57.

[20] Vaughan CP, Auvinen A, Cartwright R, et al. Impact of obesity on urinary storage symptoms: results from the FINNO study. J Urol 2013;189:1377-82.

[21] Nygaard I. Clinical practice. Idiopathic urgency urinary incontinence. N Engl J Med 2010;363:1156-62.

[22] Parazzini F, Colli E, Origgi G, et al. Risk factors for urinary incontinence in women. Eur Urol 2000;37:637-43.

[23] Tähtinen RM, Auvinen A, Cartwright R, et al. Smoking and bladder symptoms in women. Obstet Gynecol 2011;118:643-8.

[24] Higgins JP, Thompson SG. Quantifying heterogeneity in a metaanalysis. Stat Med 2002;21:1539-58.

[25] Lukacz ES, Lawrence JM, Contreras R, Nager CW, Luber KM. Parity, mode of delivery, and pelvic floor disorders. Obstet Gynecol 2006;107:1253-60.

[26] Gyhagen M, Bullarbo M, Nielsen TF, Milsom I. A comparison of the long-term consequences of vaginal delivery versus caesarean section on the prevalence, severity and bothersomeness of urinary incontinence subtypes: a national cohort study in primiparous women. BJOG 2013;120:1548-55.

[27] Rochwerg B, Elbarbary M, Jaeschke R, Walter S, Guyatt G. Understanding the results: more about odds ratios. In: Guyatt G, Meade M, Cook D, Rennie D, editors. Users' Guides to the Medical Literature: A Manual for Evidence-based Clinical Practice. ed 5. New York, NY: McGraw-Hill; 2014.
[28] Harris R, Bradburn M, Deeks J, Altman D, Harbord R, Sterne J. Metan: Fixed- and random-effects meta-analysis. Stata J 2008;8:3-28.

[29] Hannah ME, Hannah WJ, Hewson SA, Hodnett ED, Saigal S, Willan AR. Planned caesarean section versus planned vaginal birth for breech presentation at term: a randomised multicentre trial. Term Breech Trial Collaborative Group. Lancet 2000;356:1375-83.

[30] Hannah M, Whyte H, Hewson S, et al. Maternal outcomes at 2 years after planned cesarean section versus planned vaginal birth for breech presentation at term: the international randomized Term Breech Trial. Am J Obstet Gynecol 2004;191:917-27.

[31] Hannah ME, Hannah WJ, Hodnett ED, et al., Term Breech Trial 3-Month Follow-up Collaborative Group. Outcomes at 3 months after planned cesarean vs planned vaginal delivery for breech presentation at term: the international randomized Term Breech Trial. JAMA 2002;287:1822-31.

[32] Van Kessel K, Reed S, Newton K, Meier A, Lentz G. The second stage of labor and stress urinary incontinence. Am J Obstet Gynecol 2001;184:1571-5.

[33] Handa VL, Blomquist JL, Knoepp LR, Hoskey KA, McDermott KC, Muñoz A. Pelvic floor disorders 5-10 years after vaginal or cesarean childbirth. Obstet Gynecol 2011;118:777-84.

[34] Handa VL, Blomquist JL, McDermott KC, Friedman S, Munoz A. Pelvic floor disorders after vaginal birth: effect of episiotomy, perineal laceration, and operative birth. Obstet Gynecol 2012; 119:233-9.

[35] Altman D, Ekstrom A, Forsgren C, Nordenstam J, Zetterstrom J. Symptoms of anal and urinary incontinence following cesarean section or spontaneous vaginal delivery. Am J Obstet Gynecol 2007; 197, 512.e1-7.

[36] El-Azab AS, Mohamed EM, Sabra HI. The prevalence and risk factors of urinary incontinence and its influence on the quality of life among Egyptian women. Neurourol Urodyn 2007;26:783-8.

[37] Fritel X, Fauconnier A, Levet C, Benifla JL. Stress urinary incontinence 4 years after the first delivery: a retrospective cohort survey. Acta Obstet Gynecol Scand 2004;83:941-5.

[38] Fritel X, Ringa V, Varnoux N, Fauconnier A, Piault S, Breart G. Mode of delivery and severe stress incontinence. A cross-sectional study among 2,625 perimenopausal women. BJOG 2005;112:1646-51.

[39] Goldberg RP, Kwon C, Gandhi S, Atkuru LV, Sorensen M, Sand PK. Urinary incontinence among mothers of multiples: the protective effect of cesarean delivery. Am J Obstet Gynecol 2003;188: 1447-50.

[40] Handa VL, Pierce CB, Munoz A, Blomquist JL. Longitudinal changes in overactive bladder and stress incontinence among parous women. Neurourol Urodyn 2015;34:356-61.

[41] Kepenekci I, Keskinkilic B, Akinsu F, et al. Prevalence of pelvic floor disorders in the female population and the impact of age, mode of delivery, and parity. Dis Colon Rectum 2011;54:85-94.

[42] Manonai J, Poowapirom A, Kittipiboon S, Patrachai S, Udomsubpayakul U, Chittacharoen A. Female urinary incontinence: a crosssectional study from a Thai rural area. Int Urogynecol J Pelvic Floor Dysfunct 2006;17:321-5.

[43] Rortveit G, Daltveit AK, Hannestad YS, Hunskaar S, Norwegian EPINCONT study. Urinary incontinence after vaginal delivery or cesarean section. N Engl J Med 2003;348:900-7.

[44] Singh U, Agarwal P, Verma ML, Dalela D, Singh N, Shankhwar P. Prevalence and risk factors of urinary incontinence in Indian women: a hospital-based survey. Indian J Urol 2013;29:31-6.

[45] Song Y, Lin J, Li Y, et al. Analysis of risk factors about stress urinary incontinence in female [in Chinese]. Zhonghua Fu Chan Ke Za Zhi 2003;38:737-40.

[46] Yang X, Zheng H, Liao Q et al. Mode of delivery on urinary incontinence [in Chinese]. Zhonghua Fu Chan Ke Za Zhi 2004; 39:662-5. 
[47] Zhu L, Lang J, Liu C, et al. Epidemiological study of urge urinary incontinence and risk factors in China. Int Urogynecol J 2010;21: 589-93.

[48] Rortveit G, Hunskaar S. Urinary incontinence and age at the first and last delivery: the Norwegian HUNT/EPINCONT study. Am J Obstet Gynecol 2006;195:433-8.

[49] Nager C, Brubaker L, Litman H, et al. A randomized trial of urodynamic testing before stress-incontinence surgery. N Engl J Med 2012;366:1987-97.

[50] Bedretdinova D, Fritel X, Panjo H, Ringa V. Prevalence of female urinary incontinence in the general population according to different definitions and study designs. Eur Urol 2016;69:256-64.

[51] Milsom I, Altman D, Cartwright R, et al. Epidemiology of urinary incontinence (UI) and other lower urinary tract symptoms (LUTS), pelvic organ prolapse (POP) and anal incontinence (AI). In: Abrams P,
Cardozo L, Khoury S, Wein A, editors. Incontinence. ed 5. Paris, France: International Consultation on Urological Diseases; 2013. p. $15-108$.

[52] Leijonhufvud A, Lundholm C, Cnattingius S, Granath F, Andolf E, Altman D. Risks of stress urinary incontinence and pelvic organ prolapse surgery in relation to mode of childbirth. Am J Obstet Gynecol 2011;204, 70.e1-7.

[53] Volloyhaug I, Morkved S, Salvesen O, Salvesen K. Pelvic organ prolapse and incontinence $15-23$ years after first delivery: a cross-sectional study. BJOG 2015;122:964-71.

[54] Caesarean section. National Institute for Health and Care Excellence Web site. https://www.nice.org.uk/guidance/cg132. Updated November 2011. Accessed April 15, 2015.

[55] Johanson R, Newburn M, Macfarlane A. Has the medicalisation of childbirth gone too far? BMJ 2002;324:892-5.

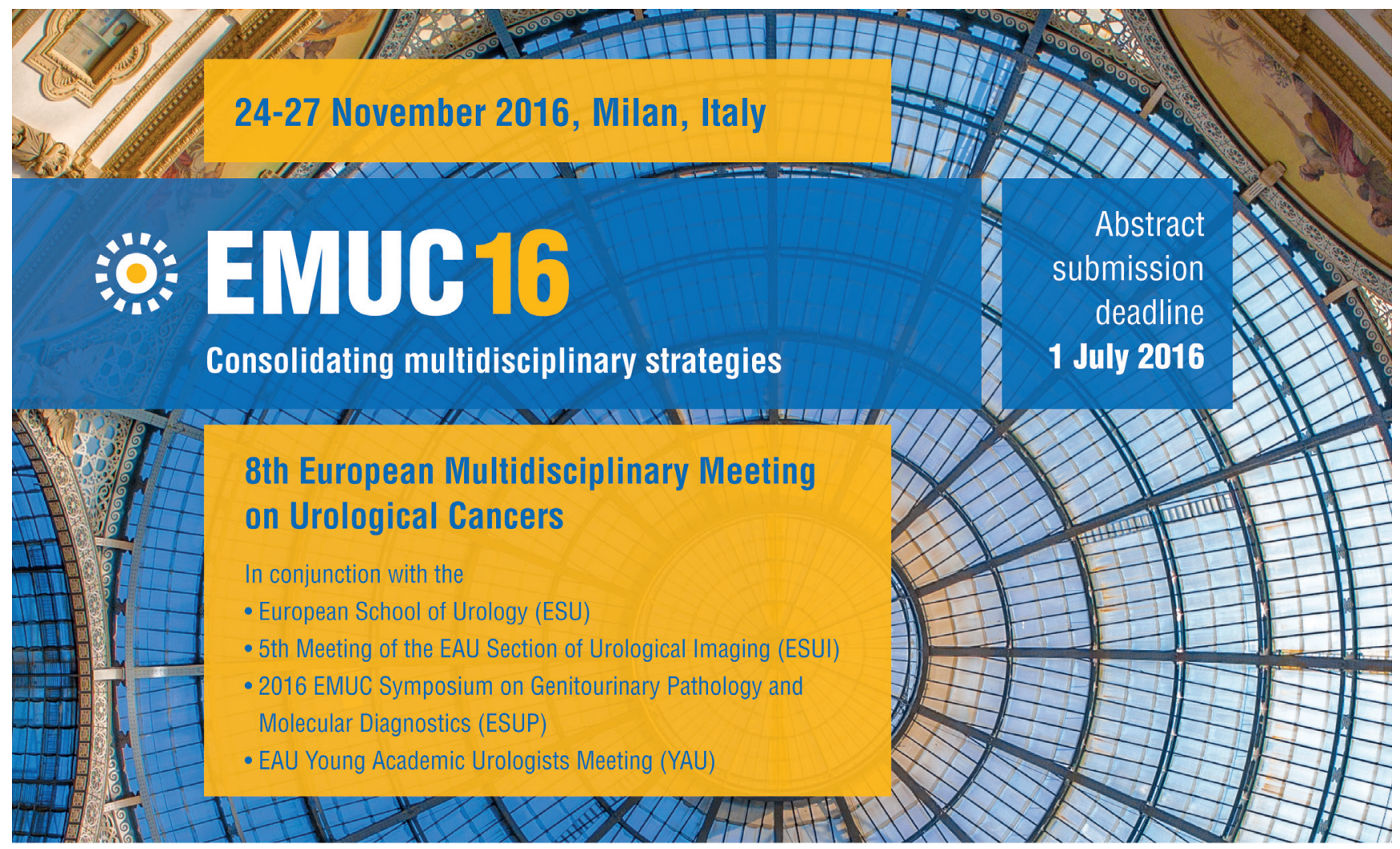

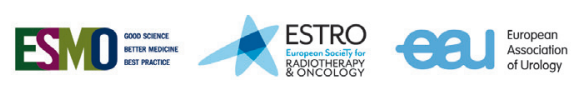

